\title{
Estimating the geographical distribution of the prevalence of the metabolic syndrome in young Mexicans
}

\author{
Miguel Murguía-Romero ${ }^{1}$, Rafael Jiménez-Flores², Rafael Villalobos-Molina ${ }^{1,3}$, Adolfo René \\ Méndez-Cruz ${ }^{2}$ \\ ${ }^{1}$ Unidad de Biomedicina, Facultad de Estudios Superiores Iztacala, Universidad Nacional Autónoma de México, \\ Tlalnepantla, México; ${ }^{2}$ Carrera de Médico Cirujano Facultad de Estudios Superiores Iztacala, Universidad \\ Nacional Autónoma de México, Tlalnepantla, México; ${ }^{3}$ Carrera de Enfermería, Facultad de Estudios Superiores \\ Iztacala, Universidad Nacional Autónoma de México, Tlalnepantla, México
}

\begin{abstract}
The geographical distribution of the metabolic syndrome (MetS) prevalence in young Mexicans (aged 17-24 years) was estimated stepwise starting from its prevalence based on the body mass index (BMI) in a study of 3,176 undergraduate students of this age group from Mexico City. To estimate the number of people with MetS by state, we multiplied its prevalence derived from the BMI range found in the Mexico City sample by the BMI proportions (range and state) obtained from the Mexico 2006 national survey on health and nutrition. Finally, to estimate the total number of young people with MetS in Mexico, its prevalence by state was multiplied by the share of young population in each state according to the National Population and Housing Census 2010. Based on these figures, we estimated the national prevalence of MetS at $15.8 \%$, the average BMI at 24.1 (standard deviation $=4.2$ ), and the prevalence of overweight people $(\mathrm{BMI} \geq 25)$ of that age group at $39.0 \%$. These results imply that 2,588,414 young Mexicans suffered from MetS in 2010. The Yucatan peninsula in the south and the Sonora state in the north showed the highest rates of MetS prevalence. The calculation of the MetS prevalence by BMI range in a sample of the population, and extrapolating it using the BMI proportions by range of the total population, was found to be a useful approach. We conclude that the BMI is a valuable public health tool to estimate MetS prevalence in the whole country, including its geographical distribution.
\end{abstract}

Keywords: Metabolic syndrome, public health, geographical distribution, young mexicans, Mexico City, Mexico.

\section{Introduction}

The metabolic syndrome (MetS) involves certain clinical findings (dyslipidemia, hyperglycemia, hypertension and obesity) and constitutes a risk factor for diabetes and cardiovascular disease, including cardiac arrest. It is a major public health problem worldwide, mainly due to overfeeding and a sedentary lifestyle (Seidell, 2000; WHO, 2000; Popkin and GordonLarsen, 2004; Conrier et al., 2008; James, 2008; Low and Chin, 2009), but the details of the interaction between the factors involved in MetS are still largely unknown (Varga et al., 2009). Although obesity, defined by the World Health Organization (WHO) as abnormal or excessive fat accumulation that may impair health (http://www.who.int/mediacentre/fact-

Corresponding author:

Miguel Murguía-Romero

Unidad de Biomedicina Facultad de Estudios Superiores Iztacala Universidad Nacional Autónoma de México.

Ave. de los Barrios 1, Los Reyes Iztacala,

Tlalnepantla 54090, México.

Tel. +52 555623 1333; Fax +52 5556231138

E-mail: miguelmurguia@gmail.com sheets/fs311/en), is recognized as a major risk for early death (Ezzati et al., 2002), its association with MetS is not constant. The American Heart Association (AHA) considers five associated factors (Table 1) of which obesity is not a mandatory part (Grundy et al., 2005; Alberti et al., 2009). Despite this, there is strong evidence at the clinical as well as the biochemical levels that abdominal adiposity plays a central role in the development of MetS (Donath and Shoelson, 2011).

The clinical entity of MetS has been questioned because of diagnostic imprecision (Reaven, 2005; Simmons et al., 2010; Reaven, 2011). However, in our opinion, MetS is still a useful definition that should be

Table 1. Reference values of anthropometric and clinical parameters of the metabolic syndrome (definition proposed by Alberti et al., 2009).

\begin{tabular}{ll}
\hline Parameter & Cut-off level \\
\hline Waist circumference & $\geq 80 \mathrm{~cm}$ in women; $\geq 90 \mathrm{~cm}$ in men \\
Blood pressure & $\geq 130 \mathrm{~mm} \mathrm{Hg}$ systolic; $\geq 85 \mathrm{~mm} \mathrm{Hg}$ diastolic \\
Triglycerides & $\geq 150 \mathrm{mg} / \mathrm{dl}$ \\
HDL cholesterol & $<50 \mathrm{mg} / \mathrm{dl}$ in women; $<40 \mathrm{mg} / \mathrm{dl}$ in men \\
Fasting glucose & $\geq 100 \mathrm{mg} / \mathrm{dl}$
\end{tabular}


considered in the evaluation framework that includes insulin resistance pathophysiology, diabetes type 2 and cardiovascular disease (Cornier et al., 2008). We also believe that knowing its geographical distribution should facilitate the design of public health strategies to manage resources optimally.

Abdominal adiposity can be indirectly estimated through two measures: body mass index (BMI) and waist circumference. Both measures have weaknesses and strengths (Szarek et al., 2009) but since the former is the more widely applied and more public health data are available based on this parameter, we decided to focus on BMI. Since obesity has a correlation to MetS prevalence (Villalpando et al., 2007; Ntandou et al., 2009), we investigated the differences in BMI range by geographical frequency to estimate how it varies depending on where in the country people live.

\section{Materials and methods}

In order to estimate MetS prevalence by state, data from four sources were collected and combined:

(i) the Mexican National Population and Housing Census 2010 (http://www.censo2010.org.mx/) whose data are reported aggregated in predefined age groups;

(ii) a truncated part of the National Census 2010 including about $10 \%$ of the total records (http://www.inegi.org.mx/est/contenidos/espanol/ soc/sis/microdatos). This part (here called the microdata) was included because each record represents an individual person, which allowed us to calculate proportions in the predefined census age groups;

(iii) the Mexican 2006 National Survey on Health and Nutrition (ENSANUT 2006) (http://www. insp.mx/encuesta-nacional-salud-y-nutricion2006.html); and

(iv) a study sample of 3,176 young people aged 17-24 years with clinical and anthropometric parameters available.

The National Institute of Statistics, Geography and Informatics (Instituto Nacional de Estadística y Geografía, INEGI), provided the two population datasets and Figure 1 shows schematically how all the datasets were utilized to harvest the information sought.

\section{The sample}

The investigation to evaluate the health of young Mexicans was carried out from 2008 to 2010. The study sample included a total of 3,176 undergraduate students, 17 to 24 years-old, randomly chosen from two public universities, one located in the eastern part,

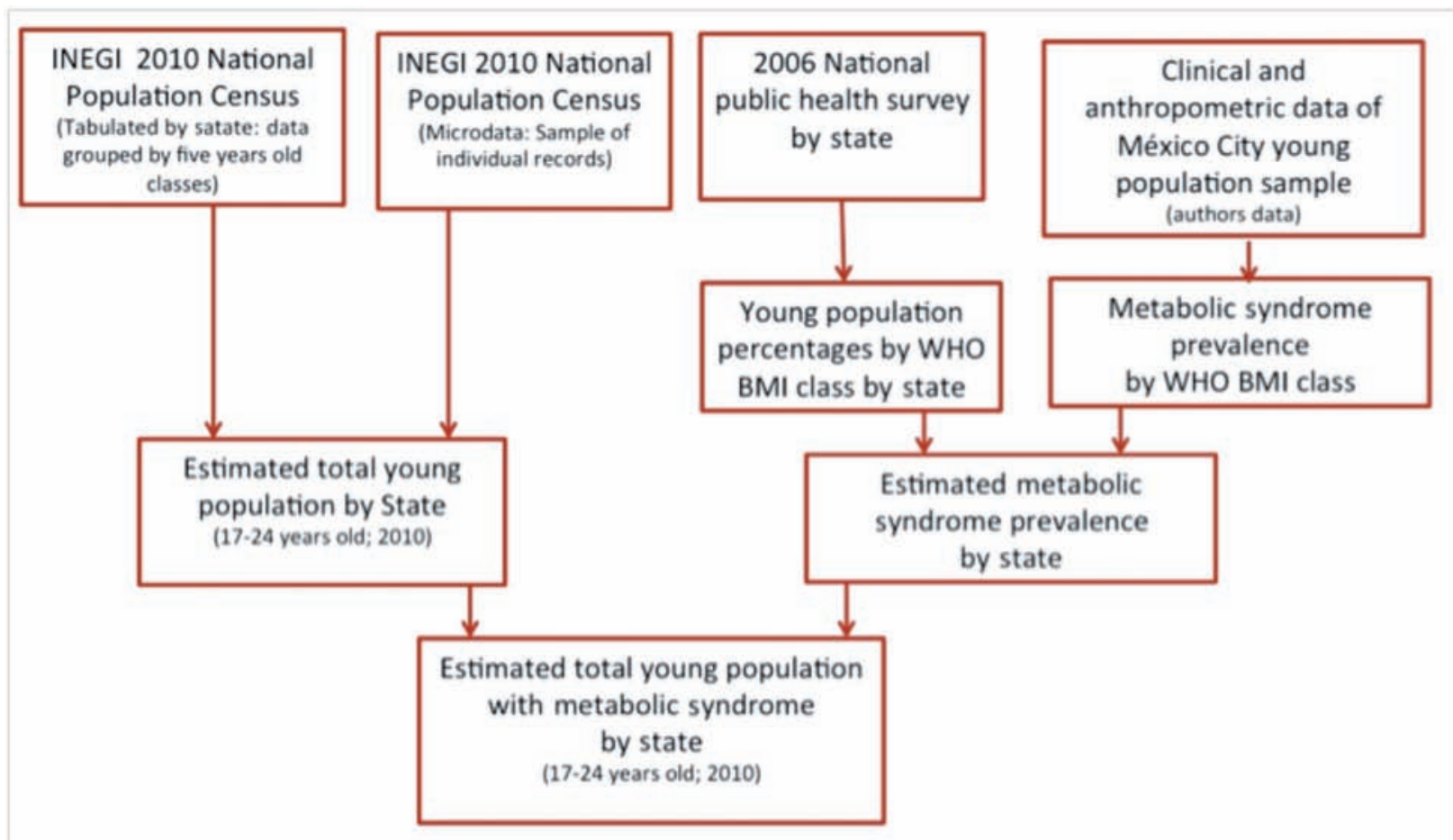

Fig. 1. Methodology to estimate MetS prevalence in young Mexicans by state. 
the other in the northern part of the Mexico City metropolitan area. All participants signed an informed consent form.

Blood samples were taken for determination of glucose, high-density lipoproteins (HDL) and triglycerides. Anthropometric data (height, weight and waist circumference + blood pressure) were collected from each student by two physicians of the team (MurguíaRomero et al., 2010). The blood samples were analyzed by CARPERMOR S.A. de C.V., a Mexican, internationally certified and accredited reference laboratory (http://www.carpermor.com.mx).

\section{BMI calculation}

The BMI was calculated for the Mexico City sample of 3,176 students and for the subjects in the records of the Mexico ENSANUT 2006, using the well-known formula:

$$
\mathrm{BMI}=\text { weight } / \text { height }^{2}
$$

where weight is measured in kilograms $(\mathrm{kg})$ and the height in meters $(\mathrm{m})$. Following the WHO recommendations, the BMI classes were divided into five groups underweight $(<18.5)$; normal range; (divided in two subclasses: 18.5 to $<23.0$, and 23.0 to $<25.0$ ); preobese $(25.0$ to $<30.0)$, and obese $(\geq 30.0)$ (http:// apps.who.int/bmi/; WHO, 1986, 1995, 2004). For both samples, only the records of persons within the target age range (17-24 years) were accepted for the study.

\section{Estimating MetS prevalence}

We estimated the MetS prevalence in the Mexico City study sample using an international definition according to Alberti et al. (2009) to create three classes (here referred to as "metabolic condition"). Students showing normal reference values (Table 1) were classified as "healthy", those with one or two results outside the normal as "undefined", and those with three or more results outside the normal limits as "MetS". We further disaggregated the data, presenting them in a $3 \times 5$ matrix of the percentages of people with the various metabolic conditions by BMI class. In order to estimate the numbers of 17-24 years old subjects in each of the three classes, including those with MetS by each state in Mexico, we extrapolated the matrix percentages to the BMI class percentages obtained from the ENSANUT 2006. The resulting proportions were multiplied by the total number of 17-24 years old in the country. To estimate the total Mexican population of the target age-range by state, we used the data from the 2010 National Population Census (http://www.censo2010.org.mx/) that presents the population in 5-year groups, choosing the ageranges of 15-19 years and 20-24 years, and the microdata sample that reports the age for each individual (http://www.inegi.org.mx/est/contenidos/espanol/soc/s is/microdatos). The first source revealed the total number of young people by state in two age ranges, 15-19 years and 20-24 years), and the second the proportion belonging to the age group of 17-19 years by state, making it possible to exclude the $15-16$ years age group and thus arrive at the 17-24 years reference group we were targeting.

Results

\section{MetS prevalence by BMI range}

The MetS prevalence in the sample of 3,176 young people in Mexico City (Table 2, Fig. 2) is ascendant with respect to BMI, i.e. there were more obese subjects $(48.6 \%)$ than underweight ones $(0.6 \%)$. All BMI classes included MetS prevalence greater than zero and, as expected, the higher the BMI class, the greater the MetS prevalence.

Table 2. Probabilities for young Mexicans to present the various metabolic condition disaggregated by BMI class.

\begin{tabular}{|c|c|c|c|c|c|c|c|c|}
\hline \multirow[b]{2}{*}{ BMI class } & \multirow[b]{2}{*}{ BMI range } & \multirow[b]{2}{*}{ Total } & \multicolumn{3}{|c|}{ Group of $17-24$ years old } & \multicolumn{3}{|c|}{ Projected probability } \\
\hline & & & Healthy & Undefined* & MetS & Healthy & Undefined* & MetS \\
\hline Underweight & $<18.5$ & 162 & 95 & 66 & 1 & $58.6 \%$ & $40.7 \%$ & $0.6 \%$ \\
\hline Normal range 1 & $18.5-<23.0$ & 1,344 & 566 & 741 & 37 & $42.1 \%$ & $55.1 \%$ & $2.8 \%$ \\
\hline Normal range 2 & $23.0-<25.0$ & 651 & 153 & 442 & 56 & $23.5 \%$ & $67.9 \%$ & $8.6 \%$ \\
\hline Pre-obese & $25.0-<30.0$ & 725 & 57 & 510 & 158 & $7.9 \%$ & $70.4 \%$ & $21.8 \%$ \\
\hline Obese & $\geq 30.0$ & 294 & 4 & 147 & 143 & $1.4 \%$ & $50.0 \%$ & $48.6 \%$ \\
\hline
\end{tabular}

* Those with alteration in one or two of the five components of MetS. 


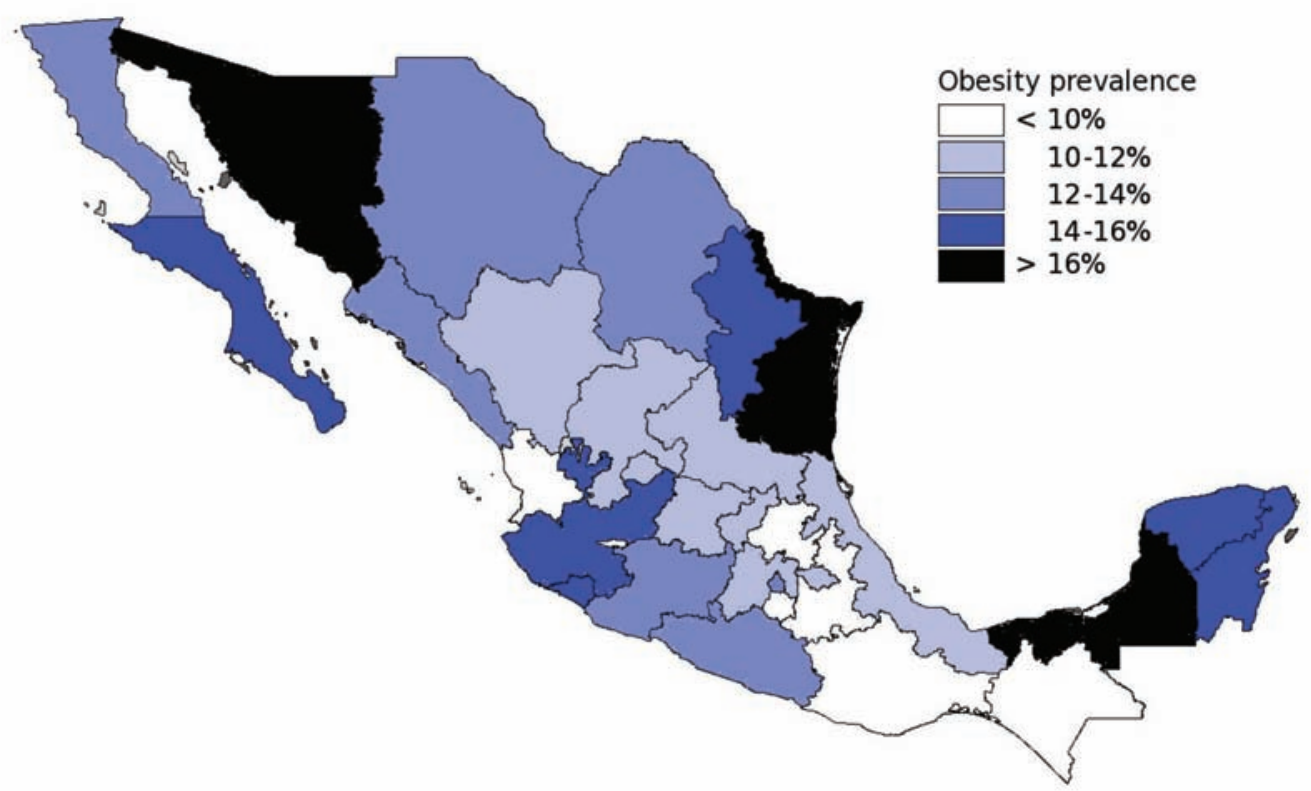

Fig. 2. Estimated obesity prevalence in young Mexicans by state. State percentage of obese people by BMI range (BMI $\geq 30)$.

\section{Population percentages by BMI range}

The data from the Mexican ENSANUT 2006 allowed us to estimate the percentages of young population by BMI class in each state (Table 3). At the national level, the estimated prevalence of underweight people was $5.7 \%$, while those within the normal range were $55.3 \%$ and those classified as overweight (pre-obese + obese) were $39.0 \%$. If the subdivisions are taken into account, the figures are $37.9 \%$ for normal range 1 with $17.4 \%$ for normal range 2 , while the pre-obese and the obese were $26.5 \%$ and

\section{$12.5 \%$, respectively.}

The percentages at the national level can be seen as the aggregation of the geographic components at the state level (Fig. 3). As can be seen, there is a wide variation from low to high values, i.e. the underweight class runs from 1.6\% (Yucatan) to 9.5\% (Chihuahua), normal range 1 from $31.4 \%$ (Yucatan) to $44.8 \%$ (Hidalgo), normal range 2 from $11.4 \%$ (San Luis Potosi) to $23.5 \%$ (Puebla), pre-obese from $19.1 \%$ (Guerrero) to $35.0 \%$ (the State of Mexico), and obese runs from $8.1 \%$ (Hidalgo) to $17.1 \%$ (Tabasco).

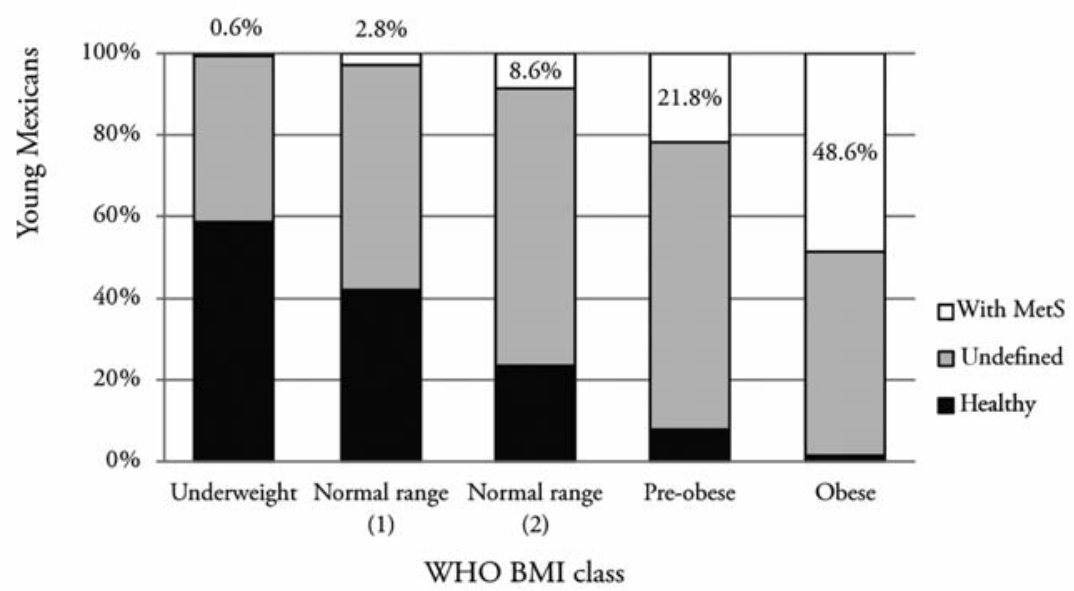

Fig. 3. MetS prevalence in Mexico City's young population (17-24 years old) grouped by BMI class. "With MetS" = young people with the metabolic syndrome; "undefined" = young people with alteration in one or two of the five components of MetS; "healthy" = young people with no alterations in any of the five MetS componentes. 
Table 3. Percentage of BMI classes of young Mexicans by state. (Based on ENSANUT 2006 - http://www.insp.mx/encuesta-nacionalsalud-y-nutricion-2006.html).

\begin{tabular}{|c|c|c|c|c|c|c|}
\hline State & Population* & Underweight & Normal range 1 & Normal range 2 & Pre-obese & Obese \\
\hline 01 Aguascalientes & 174,171 & $12,396(7.1 \%)$ & $68,181(39.1 \%)$ & $35,330(20.3 \%)$ & $40,289(23.1 \%)$ & $17,975(10.3 \%$ \\
\hline 02 Baja California & 462,535 & $36,442(7.9 \%)$ & $168,194(36.4 \%)$ & $100,917(21.8 \%)$ & $92,507(20.0 \%)$ & $64,475(13.9 \%$ \\
\hline 03 Baja California Sur & 91,230 & $6,128(6.7 \%)$ & $30,977(34.0 \%)$ & $15,999(17.5 \%)$ & $24,169(26.5 \%)$ & $13,957(15.3 \%$ \\
\hline 04 Campeche & 126,187 & $3,464(2.7 \%)$ & $44,537(35.3 \%)$ & $21,773(17.3 \%)$ & $35,629(28.2 \%)$ & $20,784(16.5 \%$ \\
\hline 05 Coahuila & 381,042 & $33,621(8.8 \%)$ & $140,089(36.8 \%)$ & $57,904(15.2 \%)$ & $97,128(25.5 \%)$ & $52,300\left(13.7^{\circ}\right.$ \\
\hline 06 Colima & 96,472 & $6,460(6.7 \%)$ & $35,316(36.6 \%)$ & $15,504(16.1 \%)$ & $25,410(26.3 \%)$ & $13,782(14.3 \%$ \\
\hline 07 Chiapas & 749,743 & $34,221(4.6 \%)$ & $320,430(42.7 \%)$ & $155,548(20.7 \%)$ & $177,325(23.7 \%)$ & $62,219(8.3 \%$ \\
\hline 08 Chihuahua & 478,187 & $45,542(9.5 \%)$ & $153,703(32.1 \%)$ & $89,186(18.7 \%)$ & $125,239(26.2 \%)$ & $64,517(13.5 \%$ \\
\hline 09 Distrito Federal & $1,205,041$ & $57,884(4.8 \%)$ & $410,451(34.1 \%)$ & $226,274(18.8 \%)$ & $347,304(28.8 \%)$ & $163,128(13.5 \%$ \\
\hline 10 Durango & 242,810 & $9,182(3.8 \%)$ & $99,981(41.2 \%)$ & $44,889(18.5 \%)$ & $60,192(24.8 \%)$ & $28,566(11.8 \%$ \\
\hline 11 Guanajuato & 829,572 & $34,710(4.2 \%)$ & $305,449(36.8 \%)$ & $149,254(18.0 \%)$ & $246,442(29.7 \%)$ & 93,71 \\
\hline 12 Guerrero & 506,191 & $23,184(4.6 \%)$ & $214,455(42.4 \%)$ & $102,398(20.2 \%)$ & $96,601(19.1 \%)$ & $69,553\left(13.7^{\circ}\right.$ \\
\hline 13 Hidalgo & 385,747 & $10,425(2.7 \%)$ & $172,767(44.8 \%)$ & $75,958(19.7 \%)$ & $95,320(24.7 \%)$ & $31,277(8.1 \%$ \\
\hline 14 Jalisco & $1,101,193$ & $99,714(9.1 \%)$ & $446,547(40.6 \%)$ & $156,075(14.2 \%)$ & $225,441(20.5 \%)$ & $173,416(15.7 \%$ \\
\hline 15 México & $2,255,862$ & $131,592(5.8 \%)$ & $817,750(36.3 \%)$ & $263,184(11.7 \%)$ & $789,552(35.0 \%)$ & $253,784(11.2 \%$ \\
\hline 16 Michoacán & & $44,139(6.7 \%)$ & $239,278(36.1 \%)$ & $123,124(18.6 \%)$ & $169,585(25.6 \%)$ & $85,954(13.0 \%$ \\
\hline 17 Morelos & 258,649 & $15,327(5.9 \%)$ & $105,376(40.7 \%)$ & $41,192(15.9 \%)$ & $75,679(29.3 \%)$ & $21,075(8.1 \%$ \\
\hline 18 Nayarit & 155,452 & $10,463(6.7 \%)$ & $61,284(39.4 \%)$ & $28,400(18.3 \%)$ & $42,600(27.4 \%)$ & $12,705(8.2 \%$ \\
\hline 19 Nuevo León & 640,103 & $53,536(8.4 \%)$ & $221,126(34.5 \%)$ & $102,416(16.0 \%)$ & $167,591(26.2 \%)$ & $95,434(14.9 \%$ \\
\hline 20 Oaxaca & 542,519 & $27,250(5.0 \%)$ & $227,908(42.0 \%)$ & $106,522(19.6 \%)$ & $128,817(23.7 \%)$ & $52,022(9.6 \%$ \\
\hline 21 Puebla & 866,186 & $19,989(2.3 \%)$ & $346,474(40.0 \%)$ & $203,221(23.5 \%)$ & $213,215(24.6 \%)$ & $83,287(9.6 \%$ \\
\hline 22 Querétaro & 272,498 & $12,433(4.6 \%)$ & $103,611(38.0 \%)$ & & & $32,120(11.8 \%$ \\
\hline 23 Quintana Roo & 211,673 & $3,884(1.8 \%)$ & $71,852(33.9 \%)$ & $35,927(17.0 \%)$ & $66,997(31.7 \%)$ & $33,013(15.6 \%$ \\
\hline 24 San Luis Potosí & 373,385 & $26,544(7.1 \%)$ & $162,803(43.6 \%)$ & $42,470(11.4 \%)$ & $102,637(27.5 \%)$ & $38,931(10.4 \%$ \\
\hline 25 Sinaloa & 403,394 & $35,279(8.7 \%)$ & $164,118(40.7 \%)$ & $64,420(16.0 \%)$ & $90,495(22.4 \%)$ & $49,082(12.2 \%$ \\
\hline 26 Sonora & 367,099 & $26,221(7.1 \%)$ & $129,468(35.3 \%)$ & $54,082(14.7 \%)$ & $86,858(23.7 \%)$ & $70,470(19.2 \%$ \\
\hline 27 Tabasco & 344,532 & $11,993(3.5 \%)$ & $122,112(35.4 \%)$ & $66,508(19.3 \%)$ & $77,411(22.5 \%)$ & $66,508(19.3 \%$ \\
\hline 28 Tamaulipas & 455,516 & $26,352(5.8 \%)$ & $165,642(36.4 \%)$ & $67,763(14.9 \%)$ & $114,820(25.2 \%)$ & $80,939(17.8 \%$ \\
\hline 29 Tlaxcala & 176,981 & $4,597(2.6 \%)$ & $74,125(41.9 \%)$ & $34,477(19.5 \%)$ & $44,245(25.0 \%)$ & $19,537(11.0 \%$ \\
\hline 30 Veracruz & $1,082,518$ & $49,206(4.5 \%)$ & $416,009(38.4 \%)$ & $214,714(19.8 \%)$ & $277,339(25.6 \%)$ & $125,250(11.6 \%$ \\
\hline 31 Yucatán & 294,945 & $4,815(1.6 \%)$ & $92,697(31.4 \%)$ & $62,601(21.2 \%)$ & $89,085(30.2 \%)$ & $45,747(15.5 \%$ \\
\hline 32 Zacatecas & 224,686 & $20,030(8.9 \%)$ & $85,346(38.0 \%)$ & $38,318(17.1 \%)$ & $57,478(25.6 \%)$ & $23,514(10.5 \%$ \\
\hline MÉXICO Country & $16,418,199$ & $937,023(5.7 \%)$ & $6,218,056(37.9 \%)$ & $2,849,190(17.4 \%)$ & $4,354,892(26.5 \%)$ & $2,059,038(12.5 \%$ \\
\hline
\end{tabular}

*Estimated number of people of the 17-24 year age group based on the National Population Census 2010 (http://www.censo2010.org.mx/) and the microdata sample of individual records of the national census (http://www.inegi.org.mx/est/contenidos/espanol/soc/sis/microdatos/).

\section{Estimation of MetS prevalence by state}

The MetS prevalence estimation based on BMI ranges was $15.8 \%$ for the whole country, varying from $13.3 \%$ in Chiapas to $18.4 \%$ in Quintana Roo (Fig. 4, Table 4). The states of Sonora and Tabasco plus those of the Yucatan peninsula (Campeche, Quintana Roo and Yucatan) showed the highest prevalence of MetS $(>18 \%)$. Hidalgo, Nayarit and the southern States of Chiapas and Oaxaca showed the lowest MetS prevalence rates $(<14 \%)$; while Sinaloa state showed the highest percentage of those regarded as healthy $(28.8 \%)$. None of the states had a proportion higher than $30 \%$ belonging to the healthy category. The three big city states (Mexico State, Distrito Federal and Nuevo Leon) showed MetS prevalence rates above the national average $(15.8 \%)$. Our estimate is that $2,588,414$ of the Mexican population aged 17-24 years belong to the MetS category (Table 4). 
Table 4. Estimated population and MetS prevalence in young Mexicans by state (based on the MetS distribution by BMI range of the study sample (Table 2), applied to the structure of BMI ranges by state (Table 3$)$ ).

\begin{tabular}{|c|c|c|c|c|}
\hline State & Population & Healthy & Undefined* & With MetS \\
\hline 01 Aguascalientes & 174,171 & $49,314(28.3 \%)$ & $100,287(57.6 \%)$ & $24,570(14.1 \%)$ \\
\hline 02 Baja California & 462,535 & $128,184(27.7 \%)$ & $263,822(57.0 \%)$ & $70,529(15.2 \%)$ \\
\hline 03 Baja California Sur & 91,230 & $23,208(25.4 \%)$ & $52,434(57.5 \%)$ & $15,588(17.1 \%)$ \\
\hline 04 Campeche & 126,187 & $30,036(23.8 \%)$ & $73,324(58.1 \%)$ & $22,827(18.1 \%)$ \\
\hline 05 Coahuila & 381,042 & $103,706(27.2 \%)$ & $216,706(56.9 \%)$ & $60,630(15.9 \%)$ \\
\hline 06 Colima & 96,472 & $25,279(26.2 \%)$ & $55,308(57.3 \%)$ & $15,885(16.5 \%)$ \\
\hline 07 Chiapas & 749,743 & $213,990(28.5 \%)$ & $435,892(58.1 \%)$ & $99,861(13.3 \%)$ \\
\hline 08 Chihuahua & 478,187 & $126,733(26.5 \%)$ & $274,124(57.3 \%)$ & $77,330(16.2 \%)$ \\
\hline 09 Distrito Federal & $1,205,041$ & $299,380(24.8 \%)$ & $702,397(58.3 \%)$ & $203,264(16.9 \%)$ \\
\hline 10 Durango & 242,810 & $65,485(27.0 \%)$ & $140,631(57.9 \%)$ & $36,694(15.1 \%)$ \\
\hline 11 Guanajuato & 829,572 & $211,902(25.5 \%)$ & $485,432(58.5 \%)$ & $132,238(15.9 \%)$ \\
\hline 12 Guerrero & 506,191 & $141,572(28.0 \%)$ & $289,199(57.1 \%)$ & $75,419(14.9 \%)$ \\
\hline 13 Hidalgo & 385,747 & $108,702(28.2 \%)$ & $225,259(58.4 \%)$ & $51,786(13.4 \%)$ \\
\hline 14 Jalisco & $1,101,193$ & $312,666(28.4 \%)$ & $615,628(55.9 \%)$ & $172,899(15.7 \%)$ \\
\hline 15 México & $2,255,862$ & $565,975(25.1 \%)$ & $1,314,328(58.3 \%)$ & $375,559(16.6 \%)$ \\
\hline 16 Michoacán & 662,080 & $175,696(26.5 \%)$ & $381,496(57.6 \%)$ & $104,888(15.8 \%)$ \\
\hline 17 Morelos & 258,649 & $71,621(27.7 \%)$ & $150,425(58.2 \%)$ & $36,603(14.2 \%)$ \\
\hline 18 Nayarit & 155,452 & $43,553(28.0 \%)$ & $90,303(58.1 \%)$ & $21,596(13.9 \%)$ \\
\hline 19 Nuevo León & 640,103 & $167,979(26.2 \%)$ & $365,234(57.1 \%)$ & $106,890(16.7 \%)$ \\
\hline 20 Oaxaca & 542,519 & $153,172(28.2 \%)$ & $314,033(57.9 \%)$ & $75,314(13.9 \%)$ \\
\hline 21 Puebla & 866,186 & $232,097(26.8 \%)$ & $509,454(58.8 \%)$ & $124,636(14.4 \%)$ \\
\hline 22 Querétaro & 272,498 & $71,872(26.4 \%)$ & $158,413(58.1 \%)$ & $42,213(15.5 \%)$ \\
\hline 23 Quintana Roo & 211,673 & $48,404(22.9 \%)$ & $124,270(58.7 \%)$ & $38,999(18.4 \%)$ \\
\hline 24 San Luis Potosí & 373,385 & $106,009(28.4 \%)$ & $213,096(57.1 \%)$ & $54,280(14.5 \%)$ \\
\hline 25 Sinaloa & 403,394 & $116,293(28.8 \%)$ & $228,486(56.6 \%)$ & $58,615(14.5 \%)$ \\
\hline 26 Sonora & 367,099 & $93,212(25.4 \%)$ & $207,268(56.5 \%)$ & $66,619(18.1 \%)$ \\
\hline 27 Tabasco & 344,532 & $84,028(24.4 \%)$ & $197,455(57.3 \%)$ & $63,048(18.3 \%)$ \\
\hline 28 Tamaulipas & 455,516 & $114,901(25.2 \%)$ & $259,379(56.9 \%)$ & $81,237(17.8 \%)$ \\
\hline 29 Tlaxcala & 176,981 & $47,516(26.8 \%)$ & $103,106(58.3 \%)$ & $26,360(14.9 \%)$ \\
\hline 30 Veracruz & $1,082,518$ & $287,988(26.6 \%)$ & $629,132(58.1 \%)$ & $165,398(15.3 \%)$ \\
\hline 31 Yucatán & 294,945 & $66,621(22.6 \%)$ & $174,213(59.1 \%)$ & $54,111(18.3 \%)$ \\
\hline 32 Zacatecas & 224,686 & $63,441(28.2 \%)$ & $128,717(57.3 \%)$ & $32,528(14.5 \%)$ \\
\hline MÉXICO country & $16,418,19$ & $4,350,536(26.5 \%)$ & $9,479,250(57.7 \%)$ & $2,588,414(15.8 \%)$ \\
\hline
\end{tabular}

*Young people with alteration in one or two of the five components of MetS

\section{Discussion}

The association of MetS prevalence rates with BMI ranges was obtained from a sample representing only two geographic units (Mexico State and Distrito Federal) and this association was used to extrapolate estimates for all the other states of the country, based on the assumption that the geographical factors involved in the geographical variation of obesity are the same as those for MetS.
The ENSANUT 2006 is a valuable database for making geographical estimations for Mexico, both at the state and the country levels; nevertheless, we suspect that MetS prevalence calculated here could be overestimated, the reason being that ENSANUT is most probably biased due to the participation of nonhealthy people in the survey. Mexico's MetS map (Fig. 2 ) shows a qualitative comparison between the states, but more studies are needed to confirm or modify these results with more reliable data. 


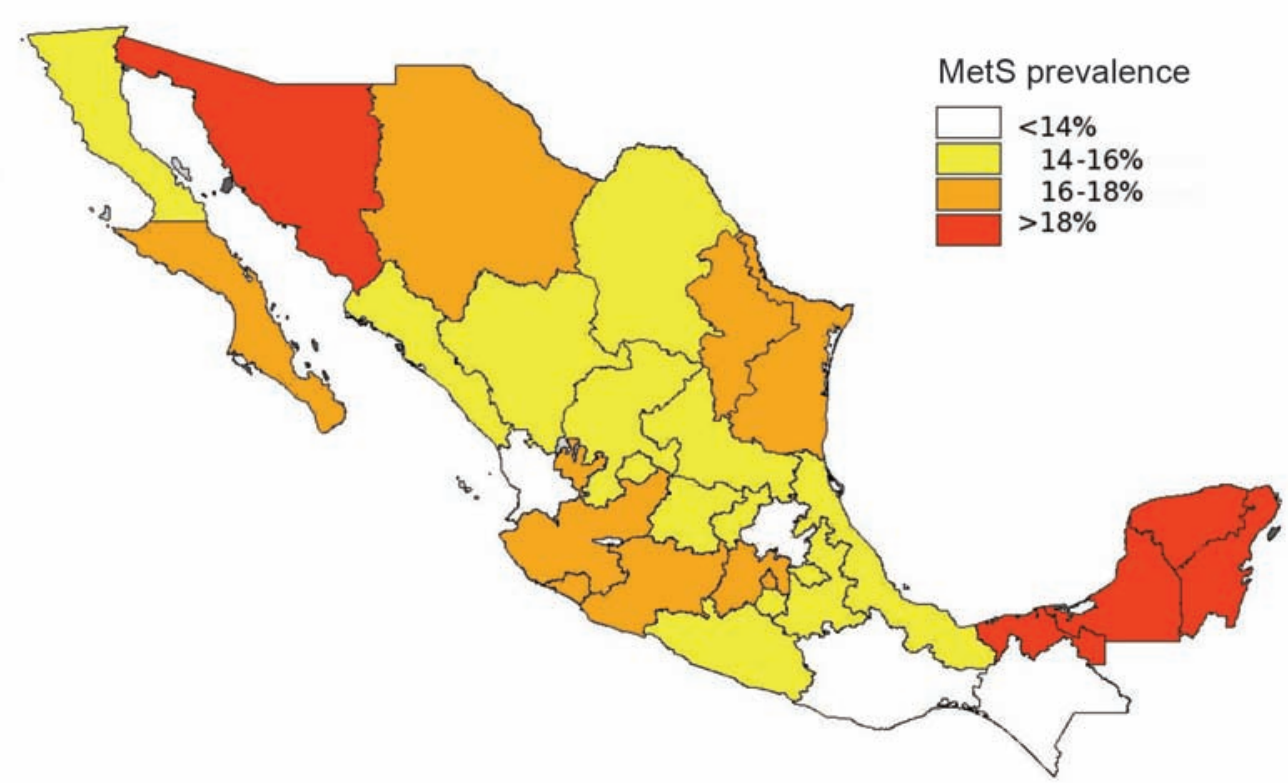

Fig. 4. Estimated MetS prevalence in young Mexicans by state (MetS definition according to Alberti et al., 2009).

The finding that all BMI classes include MetS prevalence greater than zero implies that obesity is not a mandatory factor of MetS. The fact that BMI classes "underweight" and "normal range" include MetS prevalence rates greater than zero, suggests that the naming of the BMI ranges is inadequate in the context of MetS. Thus, a more clear and contextualized meaning of the term "normal range" is required.

The methodology applied in this study recognizes clearly that there is a geographical variation of obesity (and all the other BMI classes as well). MetS and obesity have a non-homogeneous geographical distribution across the Mexican territory. Some regions present MetS prevalence higher than others resulting in a geographical pattern that can best be appreciated when judged from a map (Figs. 3 and 4). Many factors are responsible for this pattern, and there is evidence that Mexicans are genetically predisposed to MetSrelated disorders as suggested by Goodarzi et al. (2004) and Weissglas-Volkov et al. (2010). Particularly, the high prevalence estimated in southeastern Mexico could be the consequence of a genetic factor predisposing this population to MetS (SanchezCorona et al., 2004). Such genetic pre-disposal should be seen in the context of lifestyle, e.g. the evolutionary forces that acted on ancient Americans act differently now as the current population is overfed, a completely different situation compared with that of 1,000 years earlier and before. Another fact to be considered with regard to the geographical distribution of the MetS is that of the Mexican culinary diversity and abundance, which shows vast geographical differences.

The finding of a non-homogeneous geographical MetS distribution in Mexico is very valuable since it emphasizes the need to adapt prevention strategies, as well as interventions, to the regional situation.

\section{Conclusions}

The estimated MetS prevalence for Mexico according to the method proposed is $15.8 \%$. This prevalence can be geographically disaggregated, showing its variation at the state level from $13.3 \%$ to $18.4 \%$. While the states of the peninsula of Yucatan (Campeche, Quintana Roo and Yucatan), plus Sonora and Tabasco, show the highest MetS prevalence in young Mexicans, the southern states (Chiapas and Oaxaca), plus Hidalgo and Nayarit, present the lowest. More than 2,5 million young people in Mexico are estimated to have MetS, which is a current challenge and a potentially future greater risk scenario from a public health point of view.

\section{Acknowledgements}

Supported in part by grants PAPIIT IN226708, PAPIME PE204707, PAPIME PE303507 from DGAPA, U.N.A.M., PAPCA 95 2007-2008 and PAPCA 68 2009-2010 from FES Iztacala, U.N.A.M.; PICDS08-69 from ICyT-GDF. Authors are indebted to CARPERMOR, S.A. de C.V. and Universidad Autónoma de la Ciudad de México. 


\section{References}

Alberti KG, Eckel RH, Grundy SM, Zimmet PZ, Cleeman JI, Donato KA, Fruchart JC, James WP, Loria CM, Smith SC Jr, 2009. International Diabetes Federation Task Force on Epidemiology and Prevention; National Heart, Lung, and Blood Institute; American Heart Association; World Heart Federation; International Atherosclerosis Society; International Association for the Study of Obesity: Harmonizing the Metabolic Syndrome. A Joint Interim Statement of the International Diabetes Federation Task Force on Epidemiology and Prevention; National Heart, Lung, and Blood Institute; American Heart Association; World Heart Federation; International Atherosclerosis Society; and International Association for the Study of Obesity. Circulation 120, 1640-1645.

Cornier MA, Dabelea D, Hernandez TL, Lindstrom RC, Steig AJ, Stob NR, Van Pelt RE, Wang H, Eckel RH, 2008. The metabolic syndrome. Endocr Rev 29, 777-822.

Donath MY, Shoelson SE, 2011.Type 2 diabetes as an inflammatory disease. Nat Rev Immunol 11, 98-107.

Ezzati M, Lopez AD, Rodgers A, Vander Hoorn S, Murray CJ, 2002. Comparative risk assessment collaborating group: selected major risk factors and global and regional burden of disease. Lancet 360, 1347-1360.

Goodarzi MO, Guo X, Taylor KD, Quiñones MJ, Saad MF, Yang H, Hsueh WA, Rotter JI, 2004. Lipoprotein lipase is a gene for insulin resistance in Mexican Americans. Diabetes 53, 214-220.

Grundy SM, Cleeman JI, Daniels SR, Donato KA, Eckel RH, Franklin BA, Gordon DJ, Krauss RM, Savage PJ, Smith SC Jr, Spertus JA, Costa F, 2005. Diagnosis and management of the metabolic syndrome. An American heart association/national heart, lung, and blood institute scientific statement. Circulation 112, 2735-2752.

James WP, 2008. The epidemiology of obesity: the size of the problem. J Intern Med 263, 336-352.

Low S, Chin MC, 2009. Deurenberg-Yap M: review on epidemic of obesity. Ann Acad Med Singap 38, 57-59.

Murguía-Romero M, Méndez-Cruz, R, Villalobos-Molina, R, Rodríguez-Soriano NY, González-Dalhaus E, Jiménez-Flores R, 2010. Knowledge-based system for diagnosis of metabolic alterations in undergraduate students. In: Sidorov, G. (Ed.) 2010. MICAI2010 Part I. Lect Notes Artif Int 6437, SpringerVerlag Berlin Heidelberg, pp. 467-476.

Ntandou G, Delisle H, Agueh V, Fayomi B, 2009. Abdominal obesity explains the positive rural-urban gradient in the prevalence of the metabolic syndrome in Benin, West Africa. Nutr Res 29, 180-189.

Popkin BM, Gordon-Larsen P, 2004. The nutrition transition: worldwide obesity dynamics and their determinants. Int $\mathrm{J}$
Obesity 28, S2-S9.

Reaven GM, 2011. The metabolic syndrome: time to get off the merry-go-round? J Intern Med 269, 127-136.

Reaven GM, 2005. The metabolic syndrome: requiescat in pace. Clin Chem 51, 931-938.

Sánchez-Corona J, Flores-Martínez SE, Machorro-Lazo MV, Galaviz-Hernández C, Morán-Moguel MC, Perea FJ, MujicaLópez KI, Vargas-Ancona L, Laviada-Molina HA, Fernández V, Pardio J, Arroyo P, Barrera H, Hanson RL, 2004. Polymorphism MetS in candidate genes for type 2 diabetes mellitus in a Mexican population with metabolic syndrome findings. Diabetes Res Clin Pract 63, 47-55.

Seidell JC, 2000. Obesity, insulin resistance and diabetes - a worldwide epidemic. Br J Nutr 83, S6-S8.

Simmons RK, Alberti KG, Gale EA, Colagiuri S, Tuomilehto J, Qiao Q, Ramachandran A, Tajima N, BrajkovichMirchov I, Ben-Nakhi A, Reaven G, Hama Sambo B, Mendis S, Roglic G, 2010. The metabolic syndrome: useful concept or clinical tool? Report of a WHO expert consultation. Diabetologia 53, 600-605

Szarek BL, Goethe JW, Woolley SB, 2009. Assessing metabolic syndrome: waist circumference versus BMI. Schizophr Res 108, 295-296.

Varga O, Harangi M, Olsson IAS, Hansen AK, 2009. Contribution of animal models to the understanding of the metabolic syndrome: a systematic overview. Obes Rev 11, 792-807.

Villalpando S, Carrión C, Barquera S, Olaiz-Fernández G, Robledo R, 2007. Body mass index associated with hyperglycemia and alterations of components of metabolic syndrome in Mexican adolescents. Salud Publica Mexico 4, s324-s330.

Weissglas-Volkov D, Aguilar-Salinas CA, Sinsheimer JS, Riba L, Huertas-Vazquez A, Ordoñez-Sánchez ML, Rodriguez-Guillen R, Cantor RM, Tusie-Luna T, Pajukanta P, 2010. Investigation of variants identified in caucasian genome-wide association studies for plasma high-density lipoprotein cholesterol and triglycerides levels in Mexican dyslipidemic study samples. Circ Cardiovasc Genet 3, 31-38.

WHO, 1986. Use and interpretation of anthropometric indicators of nutritional status. Bull World Health Organ 64, 929941.

WHO, 1995. Physical status: the use and interpretation of anthropometry. Report of a WHO expert committee. WHO Tech Rep Ser 854, 1-452.

WHO, 2000. Obesity: preventing and managing the global epidemic. Report of a WHO consultation. WHO Tech Rep Ser $894,1-253$.

WHO, 2004. Expert Consultation. Appropriate body-mass index for Asian populations and its implications for policy and intervention strategies. Lancet 363, 157-163. 